\title{
OS FUNDAMENTOS DA BIOÉTICA EM HANS JONAS E OS LIMITES DO PRINCIPIALISMO
}

Marcelo Luiz Pelizzoli*

SÍNTESE - Trata-se de, ao expor o andamento de nossa pesquisa em Fundamentos da Bioética, apontar os limites das (bio)éticas tradicionais, no caso exemplar do Principialismo, para então investigar a base da proposta de Hans Jonas como alternativa de fundamento contemporâneo para a Bioética - a sua humanização face à civilização tecnocêntrica.

PALAVRAS-CHAVE - Fundamentos filosóficos. Bioética. Principialismo. Civilização tecnológica.
ABSTRACT - This essay aims to, in the exposure of the development of our "bio"ethics fundaments resarch, point out the exemplary case of principialism, for then investigate the proposal base by Hans Jonas as an altemative of contemporary fundaments for "bio"ethics - your humanization in face of technocentric civilization.

KEY WORDS - Philosophic fundaments. Bioethics. Principialism. Technological civilization.

\section{Contexto e caracterização desta investigação}

Esse estudo integra nosso projeto e grupo de pesquisa em Ética e Bioética, na linha Problemas de Ética e Filosofia Politica da Universidade Federal do Pernambuco. Trata-se de linha de pesquisa fundamental em nosso âmbito de atuação, investigando a transformação da Ética em Bioética, nas interfaces da tecnologia com a Saúde e o Ambiente, pesquisada desde fundamentos filosóficos contemporâneos, e sem negligenciar a resolução de problemas práticos demandados por tais áreas. Refletimos sobre os modelos teóricos nas visões de Sujeito, Natureza, Doença, e os conceitos em torno dos grandes temas da Ética Aplicada. Este é hoje com certeza um dos campos de maior relevância social e alcance de pesquisa e extensão da Filosofia, tradicionalmente voltada ao desenvolvimento da teoria/especulação pura. O nosso interesse nos problemas da Ética Aplicada ou Filosofia Prática deve-se a essa possibilidade de alargamento da relevância acadêmica, em termos de extensão, com referência a temas sociais de extrema importância, bem

Professor. Doutor. Universidade Federal do Pernambuco, Recife.

\begin{tabular}{|l|l|l|l|l|l|}
\hline VERITAS & Porto Alegre & v. 50 & n. 2 & Junho 2005 & p. 111-124 \\
\hline
\end{tabular}


como de interdisciplinaridade e intercâmbio de saberes de áreas afins ou mesmo aparentemente distantes, como a Filosofia e a Medicina.

Certamente, estamos cientes da amplitude da Bioética e da Filosofia prática, que abrangem temas que vão da ética ecológica, Direito ("biodireito", direito ambiental), Teologia, áreas biomédicas, até temáticas de ponta nas ciências sociais, como desenvolvimento sustentável, interculturalidade e ramos afins. Por conseguinte, a base das pesquisas, a estrutura teórica ampla de retaguarda, contempla uma boa margem de flexibilidade em relação às temáticas citadas, na confluência da Filosofia e da Ética da tradição filosófica em sua multiplicidade, voltadas aos temas de relevância social e ambiental surpreendentes - em especial agora, no âmbito da racionalidade tecnocêntrica, mediando as relações humanas, no contexto dos (des)controles e embates daquela com a Natureza (humana).

\section{Em busca de fundamentos para a competência crítico-normativa da filosofia em face da Bioética}

Neste sentido, é correto partir de uma visão abrangente e interdisciplinar, mas essencialmente fundamentadora, pelas novas exigências epistemológicas diante dos dilemas éticos emergentes, típicos de áreas complexas e interdependentes, em busca de consolidação de categorias simultaneamente sólidas e profícuas em termos filosóficos; por conseguinte, o que nos propomos questionar é a existência de limitações intrínsecas nas metodologias e práticas deontológicas tradicionais (decorrentes das relações entre profissionais de saúde e pacientes mediados pela tecnologia), em especial o principialismo, como sentido e resolução suficiente em Bioética, dentro da racionalidade tecnocêntrica. É preciso confrontá-los à luz de fundamentações ético-filosóficas contemporâneas inovadoras, exemplificadas, aqui, na reorientação de Hans Jonas, ao mesmo tempo inserida no sentido aberto e dialogal-dialético na Bioética, como vem se configurando nas pesquisas e nos Comitês de Ética em Pesquisa no Brasil. Aqui, temos o mote filosófico par excellence: é necessário levantar e refletir criticamente acerca das visões medicalizantes/beneficientes objetificadoras, mesmo desde o interior do corpus da ética da tradição deontológica (começando em Kant em especial) até chegar ao predomínio do principialismo na Bioética (anglo-saxônica em especial), e isto criticamente, à luz dos novos desafios sociais bioéticos e da plausível recuperação da competência crítico-normativa por parte da filosofia com relação aos problemas concretos do agir pessoal, social e político atuais. $\mathrm{O}$ aporte paradigmático para uma tal crítica pode ser, entre outros, a "bioética" para a civilização tecnológica, de Hans Jonas; mais explicitamente: a bioética hoje, principalmente em contexto norteamericano, fundamenta-se nos quatro princípios básicos exemplarmente trabalhados na obra de Beauchamp e Childress, Principles of Biomedical Ethics (4. ed., New York: Oxford, 1994). São eles: autonomia, beneficiência, não-maleficiência e justiça. Representam a culminância de uma busca de normatização dos procedimentos médicos e de pesquisa biomédica diante de seu histórico altamente desumanizador, no processo de avanço tecnológico na área às custas de cobaias 
humanas, instrumentalização da relação de cura, bem como dilapidação dos saberes tradicionais e limites e reveses da intervenção tecnológica na natureza (humana). E, não obstante sua inegável importância, eles se mostram insuficientes para abordar a relação biomédica que se instaura às custas da alteridade do paciente (ou da Natureza), responsabilidade, solidariedade e mesmo o próprio princípio de justiça, que entraria na questão da economia da saúde, acesso às condições de saúde, desigualdade social, entre outros. Em suma, tais princípios são bastante restritos a uma abordagem da moral privada, onde o princípio mais criticado aqui é o de justiça, pois não ultrapassa, de modo geral, as obrigações estritamente terapêuticas e de direitos do paciente, não alcançando, por conseguinte, o grosso da realidade social envolvida, em especial no caso dos países do Terceiro Mundo.

Neste sentido, trazemos à baila posturas teóricas da responsabilidade radical do sujeito diante da ameaça da racionalidade instrumental/tecnocêntrica, bem como o da solidariedade e alteridade, que resgatam a ética da humanização pela intersubjetividade antes de toda mediação, e da precedência do outro como outro, como fundamentos que podem suportar diretrizes e formulações de normas de interesse bioético para além do viés principialista.

Problemas específicos vão revelar-se em torno daquela relação explicitada, no veio da abordagem ética da responsabilidade (o sentido metafísico e mesmo natural do humano na civilização tecnológica ameaçadora do sentido humano) e da alteridade (como são tratadas as "figuras da alteridade": o outro como outro fundamentalmente, a vis medicatrix naturae, o sentido psicológico da doença, os vulneráveis, etc.); ou seja, vem à tona a relação epistemológica do saber mediador entre os sujeitos plurais (diferentes) e com dignidade própria diante da conseqüente estrutura relacional da mediação da tecnologia e suas "vinganças". Quanto a isso, inspira nossa análise a excelente obra de Tenner, A Vingança da tecnologia, além, certamente, de Das Prinzip Verantwortung - Versuch einer Ethik für die Technologische Zivilisation", e Técnica, medicina y ética, ambas de H. Jonas. São presentes igualmente, nesta trajetória incipiente, as críticas epistemológicas aos efeitos do chamado "paradigma cartesiano" na Saúde, visto que não se trata apenas, com Bioética, de instituir algum código novo de normatividade para a Saúde (cf. Pelizzoli, 2003 e 2003 ${ }^{\mathrm{a}}$.

\section{No cerne da questão: dos limites epistemológicos à postura da humanização crítica e do diálogo}

Em termos filosóficos fundacionais, típico de nosso âmbito de atuação filosófico-reflexivo, escolhemos recorrer ao Princípio... de Hans Jonas, ${ }^{1}$ para que o questionamento ético seja mais profundo, apontando naturalmente para os limites epistemológicos dos modelos éticos tradicionais. Não obstante, toda orientação teórica a que se chegar a partir daí só vai haurir sentido desde o jogo de dilemas e

Em outro momento apoiado com a ética como responsabilidade, de Levinas, em especial com a obra Totalidade e Infinito (1964); mas também na crítica à técnica de Heidegger e Gadamer. 
possiveis resoluções de casos discutidos no aberto da pluralidade de interesses e posturas de pensamento diversas, típico de uma Bioética aberta dos tempos plurais. Ou seja, metodologicamente, trata-se de operar com a postura da abertura (e incerteza) de princípios últimos (fundamentos), na medida da entrada em cena do diálogo e dialética das ações e dos saberes, mesmo que, e exatamente porque, apoiada nos ideais reguladores da defesa da alteridade em meio à homogeneização da racionalidade técnica sobre o sentido vital-humano. Hans Jonas, propriamente, se movimenta no estabelecimento de uma 'metafísica naturalista' moldada numa "ética da alteridade" vivida como responsabilidade radical, em vista da sobrevivência das espécies, e propugna, conseqüentemente, uma ética ancorada no natural. Diante disso, há a intermitente crítica à racionalidade técnica às custas da Natureza (humana), como cabe a um bom discípulo de Heidegger, mesmo que postado na tradição judaica. Fique claro, por conseguinte, que o procedimento metodológico deve centrar-se na crítica aos princípios tradicionais da Bioética à luz da necessária crítica e diálogo para o estabelecimento do valor da ética da responsabilidade e da alteridade.

As primeiras publicações em Bioética, representadas exemplarmente por Principles of biomedical Ethics e também Moral problems in Medicine (vide bibliografia), recorrem a uma tradição filosófica pautada em princípios éticos fundamentais tradicionais, a saber, como instância última (intocada) mediadora dos conflitos morais, o que pautou a estrutura de pensamento e a operatividade (pragmática) da Bioética. Como ícones, temos um arco de pensadores que vai de Hipócrates e Aristóteles até Kant, mas também S. Mill e J. Bentham. Isso permitiria transpor a incomensurabilidade dos conflitos ((bio)éticos) ao apelar para o estatuto moral do ser humano acima das contingências das culturas e moralidades variadas e conflitantes; porém, sublima-se com isso as contingências do indivíduo e se minimiza simultaneamente o papel da intervenção mediadora artificializada da tecnologia sobre o indivíduo - já que este, pelo menos, não é um "meio, mas um fim em si mesmo". Esta defesa de um tribunal ético para além das contingências que ao mesmo tempo prescinde do papel da alteração da(s) essência(s) do(s) homem(s) e da Natureza (conformação à ordem natural, vis medicatrix naturae) pela via tecnológica biomédica, marca o impulso inicial à estruturação da Bioética na pesquisa acadêmica, e tem papel importante em vista da segurança de decisões e da pragmática dos dilemas em jogo. ${ }^{2}$

Não obstante, percebe-se um determinado vácuo crítico-reflexivo de um realismo e fundacionismo de princípios inventariados a partir de um ser humano genérico, no interior de estruturas argumentativas ideais pautadas num ser humano cumpridor de deveres como referência simbólica última. Há um vácuo e zona de silêncio teórico-crítico quanto à diversidade (e até a ausência) de sentido da categoria filosófica de "humano" por um lado, e, por outro, quanto à relação instaurada na mediação tecnológica sócio-cultural dos indivíduos. Tais teorias não

2 Quanto a este tema, veja-se o trabalho de Débora Diniz, em: $O$ que é bioética? São Paulo: Brasiliense, 2002. 
são capacitadas a lidar com a dificuldade da pluralidade humana, e principalmente com o alargamento do princípio de justiça, na medida em que este é apenas o reconhecimento da necessidade de beneficência, não entrando em questões de base como acesso aos bens, desigualdade social, visão de corpo humano como máquina, etc. A isto se liga o fraco questionamento do vetor de dano humano da mediação total da tecnologia, na medida mesma da sua presumida resolução dos conflitos da moralidade, seja no aborto, seja no transplante, seja diante da venda de órgãos, seja na eutanásia e outros.

A crítica epistemológica ao paradigma cartesiano na Medicina entra exemplarmente aqui, na conjunção da desconstrução da "metafísica da técnica", propondo ir em direção a uma "metafísica da alteridade" que inclui o sentido das seres não-humanos bem como uma sabedoria harmônico-dinâmica dos fins (telos) da Natureza, como em Hans Jonas. ${ }^{3}$ Se não podemos haurir tais pressupostos epistemológico-operativos para a (bio)ética a partir de Levinas como tal devido ao seu abandono da especulação da metafísica da natureza não-humana, devido à sua tradição bíblico-judaica pesadamente carregada do núcleo antropológico ético-mítico dos "povos do deserto", nem por isso o coração da questão está lançado, tomando a forma da irredutibilidade da alteridade como fulcro da subjetividade, na medida do acontecimento da humanidade do homem como singularidade atravessada pelo Desejo do Outro, caminho belamente traçado como genealogia do sujeito em Totalidade e Infinito, de Levinas. O Princípio de Jonas, aqui, é como que o ponto dialético de junção da crítica à técnica e à dilapidação da essência da Natureza e do Homem em Heidegger e na hermenêutica de Gadamer, e a defesa da alteridade radical na relação ética de base bíblica em Levinas. Tal pensamento se mostra altamente profícuo em termos de discussão de fundamentos filosóficos e epistemológicos (aqui como teoria crítica da ciência diante do viés da tecnologia objetificadora), inseparáveis dos fundamentos éticos que guiam o resgate da natureza humana/alteridade em meio às suas transformações sofridas - devido à imposição metodológica de tal paradigma objetificador. ${ }^{4}$

$\mathrm{O}$ que deve se seguir daí é a discussão e formação continuada frente aos casos e dilemas trazidos pela Bioética, seja nas "situações emergentes", seja nas "situações persistentes", à luz de novas possibilidades crítico-normativas, ou seja, não mais pautadas nos pressupostos da Bioética dos primeiro 20 anos de sua história, a saber: (1) ser humano sujeito de deveres e direitos genérico, fora da diversidade ético-cultural e incerteza de princípios, (2) subestimação da intervenção tecnológica como alteração da natureza humana e crença exagerada em seu potencial de beneficência, na esteira do paradigma cartesiano objetificador (3) desconhecimento ou descarte das posturas da responsabilidade radical/alteridade,

3 Cf. Princípio responsabilidade, cap. 3 e 4.

4 Cf. Pelizzoli, 1999, 2003 e 2003a. Aqui entra em jogo o papel opressivo do estatuto epistemológico das ciências naturais diante das ciências humanas; já a Bioética mostra que a Medicina, por exemplo, é também uma "ciência humana". Veja-se a obra de Paulo Henrique Martins, Contra a desumanização da medicina, Vozes, 2003 
incluindo o alargamento do "princípio" de justiça no contexto da desigualdade socioeconômica e conflito de valores - a que o saber biomédico está confrontado no capitalismo.

\section{O Princípio de Hans Jonas}

O Princípio responsabilidade, de Hans Jonas (1903-1993), escrito em 1979, busca ser um "ensaio de uma ética para a civilização tecnológica", ou, ainda, um tractatus ethico-technologicus. Para compreender melhor este autor, é preciso ter em mente o seguinte contexto e influências: (1) A ética judaica, ligando-se aqui à questão da Alteridade. (2) A violência das guerras e do nazismo, fascismo e comunismo. (3) O pensamento de Heidegger (de quem Jonas foi aluno), em especial a crítica à técnica e a ameaça à essência humana. (4) Os trabalhos sobre a Gnose. (5) O debate com o Marxismo. (6) O florescimento da Bioética em nível institucional e acadêmico. Não obstante, vamos simplesmente seguir alguns dos passos fundamentais da obra citada, expostos no seu capítulo I.

O primeiro fato é o de que "PROMETEU está desencadeado". Ou seja, a ciência compõe forças de penetração nunca antes conhecidas; a Economia age com infatigável impulso de dominação; somado a isso, temos o vazio de referências e o relativismo de valores atuais. A crise é, pois, o ponto de partida. "O que poderá servir-nos de guia?", pergunta ele. E responde: o próprio perigo que prevemos, de onde se poderá descobrir princípios éticos dos quais derivam novos deveres do novo poder. "A isto eu chamo 'heurística do temor'" - como que freios éticos voluntários aos tentáculos deste poder (cf. 15-16). ${ }^{5}$

A heurística do temor é ligada diretamente ao princípio de precaução, e começa assim: Somente a previsivel desfiguração do homem nos ajuda a alcançar aquele conceito de homem que há de ser preservado de tais perigos. Ou seja, é porque temos alguma noção de dignidade humana e vital a ser preservada que podemos e devemos pedir uma moral que a defenda. O que vai chamar a atenção, nesta ética, é que sua justificação prolonga-se até a metafísica, pois "somente desde ela que cabe fazer a pergunta da razão pela qual deve haver em geral homens no mundo... e garantir a sua existência futura". Mas esta metafísica, podemos dizer, será alargada, deixando de ser antropocêntrica para incluir a dignidade de todos os seres "do globo terrestre", bem como o "futuro remoto", pois, acima de tudo, não podemos viver como se fôssemos a última geração, como dizia José Lutzemberger. A luta desta ética fundamentada metafisicamente parte do fato de que viver e manter a vida é melhor do que deixar morrer ou aniquilar, e trava-se contra um certo utopismo tecnocêntrico, que também alardeia um futuro novo, porém nitidamente objetifificador, ou seja, "esquecedor" do Ser abismal que atravessa o homem (Heidegger), ou, indiretamente, de sua morada na alteridade (Levinas). "A dinâmica tecnológica de progresso, que é de escala planetária, alberga

5 Os números que aparecem sem referência dizem respeito à obra de Jonas, Princípio responsabilidade, e as páginas referentes à tradução em espanhol. 
enquanto tal um utopismo implícito..." Já o princípio de responsabilidade tem uma "tarefa mais modesta, decretada pelo temor e o respeito: preservar a permanente ambigüidade da liberdade do homem... preservar a integridade de seu mundo e de sua essência frente aos abusos do poder" (cf. 16-17). Ou seja, está claro que a objetificação tecnocêntrica não respeita a abertura e alteridade que é a humanidade do homem, e, conseqüentemente, da "natureza natural". O papel objetificador ('entificador do ser' como diria Heidegger) é apontado claramente no "dinamismo acumulativo dos desenvolvimentos técnicos", quando "os desenvolvimentos postos em marcha pela ação tecnológica com vistas a metas próximas tendem a fazer-se autônomos, ou seja, adquirir seu próprio dinamismo inevitável... O que uma vez começou nos arrebata o controle da ação, e os fatos consumados que aquele começo forjou se convertem acumulativamente em lei de sua continuação". É esta possibilidade da bola de neve irrefreável que assusta o autor e o faz entrar numa certa pedagogia da catástrofe, com a sua heurística do temor e o alerta da precaução (cf. 72-73). ${ }^{6}$

Em termos concretamente éticos, da ação, cabe agora o ponto de partida, o do caráter modificado da ação humana. A saber, no momento em que não temos a certeza e segurança dos frutos de nossa ação - e as questões ecológicas e éticas estão aí para nos mostrar perigos reais -, ou seja, nesse momento de um certo fascínio combinado com medo e expectativas imprevisíveis em jogo nos avanços do "progresso", é aí que se abre uma dimensão de valoração ética nova, que não estava prevista nos "cânones da ética tradicional" (cf. 22-23).

$\mathrm{Na}$ consideração da obra da civilização tecnológica, o discurso de Jonas nos lembra o da Deep ecology, corrente ecológica marcante até hoje. "O angustiante poder do homem fala de sua violadora invasão da ordem cósmica, da temerária imupção do inesgotável engenho humano nos diversos campos da natureza. ... o artefato da cidade. A profanação da natureza. e a civilização vão juntas. Ambas se rebelam contra os elementos..." (27) Não obstante, o mais importante para nosso caso não é tanto o tom alarmante, mas o fato de que nisso, a natureza "não era objeto da responsabilidade humana; ela cuidava de si mesma" e cuidava também do homem; ou seja "frente à natureza não se fazia uso da ética, senão da inteligência e da capacidade de invenção" (28) ${ }^{7}$. E agora, portanto, reconhecendo os limites da Ética da tradição, precisamos pensar um novo estatuto moral diante da dinâmica dos desafios presentes. Vejamos porém, antes, algumas características da ética tradicional, segundo Jonas.

\footnotetext{
6 Jonas opõe-se nitidamente contra o vazio ético vigente na atualidade. "Agora balançamos diante da desnudez de um niilismo no qual um poder máximo vai emparelhado com um máximo vazio, e uma máxima capacidade vai emparelhada com um minimo de saber sobre ela." (58).

7 Nesse ponto, Jonas cita o Exemplo da Antígona de Sófocles, aqui algumas partes: "Muitas são as maravilhas do mundo, mas o homem supera-as todas. [...] ele avança e atravessa as empoladas ondas do mar que rugem. Afadiga a Terra... ao guiar as charruas revolvendo-a com a raça eqüina. Ele persegue e depreda as alegres familias dos pássaros. Com redes captura as espécies animais selvagens... Ele... Sabe defender-se do frio inóspito, e das fustigantes chuvas. Sagaz e sem medo enfrenta o futuro. Só não pode encontrar salvação contra o Hades, embora saiba curar males sem remédio. ...caminha para o mal ou para o bem... (Apud Jonas, 29)
} 


\section{Características da ética havida até agora, segundo Jonas}

Na denúncia da tradição ética, o autor aponta os seguintes limites:

1. a atuação sobre os objetos não humanos não constituía um âmbito de relevância ética.

2. O que tinha relevância ética era o trato direto do homem com o homem, incluindo o trato consigo mesmo; toda ética tradicional é antropocêntrica.

3. A entidade "homem" e sua condição fundamental eram vistas como constantes em sua essência e não como objeto de uma techne (arte) transformadora.

4. O bem e o mal da ação residiam nas proximidades do ato, ou na práxis mesma, ou no alcance imediato; não eram assunto de uma planificação distante. (cf. 29).

O ponto um e dois são semelhantes, e o fundamental nessas avaliações é que isso deve gerar novas dimensões de responsabilidade, a complementar as dimensões da ética "próxima" que já conhecemos; chamando-nos à atenção especialmente a passagem da moral de estilo privado para a dimensão da responsabilidade no nível social e planetário. "Certamente, os velhos preceitos dessa ética "próxima" - justiça, caridade, honradez etc - seguem vigentes em sua imediatez íntima para a esfera diária, próxima, dos efeitos humanos recíprocos. Mas esta esfera resta eclipsada por um crescente alcance do obrar coletivo, no qual o agente, a ação e o efeito não são já os mesmos... o que impõe à ética uma dimensão nova, nunca antes sonhada, de responsabilidade." (32).

Podemos perceber que a tônica da responsabilidade radical, ontológica, e, mais adiante, profundamente objetiva, marca a obra Princípio responsabilidade de Jonas. A tarefa da ética parte desses pressupostos da crise, ameaça, e de que a humanidade se levante contra o perigo; o que aparece eminentemente é a vulnerabilidade da natureza e da natureza humana. Esse é o chamariz ético, no sentido do cuidado com a alteridade, como veremos ao fim, o que ao nosso entender liga a inspiração de dois autores próximos e distintos: Heidegger e Lévinas. ${ }^{8}$ A fragilidade dos ecossistemas, da biosfera inteira, como diz Jonas, é que agora é objeto da consideração da ação normativa e valorativa em vista do caráter ameaçador da ação humana. Fato evidente é a nossa dependência absoluta em relação aos seres naturais; mas, como pergunta Jonas, quanto à classe de obrigação em jogo, “trata-se de algo mais que de um interesse utilitário? Se trata só da prudência de não matar a galinha dos ovos de ouro...?" (cf. 33).

É aqui que se introduz o novo papel do saber na moral, e o alerta ecológico antigo de que a própria condição de imprevisibilidade de fatores, com algum risco de ameaça, deve ser parte já da negativa para certo tipo de intervenção do progresso tecno-econômico. Neste contexto, "o saber se converte em um dever urgente, que transcende tudo o que anteriormente se exigiu dele: o saber há de ser

Quanto a isso cf. nossos livros O Eu e a diferença: Husserl e Heidegger e Levinas: a reconstrução da subjetividade, ambos: Porto Alegre: EDIPUCRS, 2002. 
de igual escala que a extensão causal de nossa ação. O reconhecimento da ignorância será, pois, o reverso do dever de saber e, deste modo, será uma parte da ética [...] dar conta das condições globais de nossa vida humana e o futuro remoto e a existência mesma da espécie" (35).

\section{Novos direitos e deveres: destinação do ser humano}

Nesta evidente busca de concepção nova de direitos e deveres, é que se discute a ventilada questão da natureza como portadora ou não de um direito moral próprio, para além do interesse humano. Para ele isso é evidente, implicando em "ampliar o reconhecimento de 'fins em si mesmos' mais além da esfera humana e incorporar ao conceito de bem humano o cuidado daqueles seres". Aqui, mais uma vez se justifica, para o autor, a passagem da ética à metafísica, indo "da doutrina da ação à doutrina do ser", pois, para ele, toda ética funda-se na base ontológica, haurindo dali sua justificação natural-social e seu sentido de ação em vista de fins (cf. 35). Adiantamos que, é como se Jonas trouxesse um fundamento metafísico provindo de uma natureza posta em nós, uma essência que ao mesmo tempo não se congela em biologicismo pois contempla a ambigüidade da liberdade humana e do caráter cultural e social do que somos. Para isso, é preciso, partindo sempre da subjetividade alterada que somos no mundo da técnica, perguntar pela essência do homem, de modo que a sua descrição ontológica (e mundana, mundo e natureza ao mesmo tempo) apresente imediatamente uma demanda ética, próximo ao que faz Levinas quando funda a ontologia na ética, e, paradoxalmente, quando Heidegger funda a ontologia e a moral na ontologia fundamental.

Para isso não se pode desviar de que, como diz Heidegger, há uma destinação do homem no seio da técnica. Jonas toca em algo como "a tecnologia como "vocação" humana". Somos já sujeitos e objetos desta destinação, de nosso próprio fruto; somos parte dele, e não se trata de arrancar-nos completamente desta destinação. Por outro lado, o tom jonasiano toca o romantismo e a crítica radical à técnica, no sentido de que o homo faber está atropelando o homo sapiens, e podendo fazer perdeu o seu sentido humano. "A técnica se transformou num infinito impulso, em cujo contínuo progresso que se supera se tenta ver a missão da humanidade... O triunfo do homo faber sobre seu objeto externo representa seu triunfo dentro da constituição íntima do homo sapiens, do qual sói ser em outros tempos servidor" (36)

Sim, "vencemos" a natureza bravia e isso ainda é fascinante, como o brilho dos novos aparelhos eletrônicos ou midiáticos; mas que sujeito é esse por trás desta materialidade cada vez mais dinâmica e ofuscante? Novamente se introduz a questão: quem é verdadeiramente o homem? A resposta de Jonas revela mais uma de suas influências especiais, a do marxismo renovado e das políticas de emancipação. "É o ator coletivo... Isto exige nova classe de imperativos. Se a esfera da produção invadiu o espaço da ação essencial, a moral terá que invadir a esfera da produção... na forma da política pública" (37). Todo o último capítulo do 
Princípio... é dedicado ao tema das políticas públicas, Estado e Governo e a esfera de ação coletiva, contemplando críticas ao marxismo e retomando certas inspirações de mesma ordem.

Continuando a questão da destinação, se há uma vocação técnica evidente na humanidade do homem, ao investigarmos ontológica, natural e socialmente, que outra vocação encontramos? A vocação ética. Aqui, primeiramente um chamado interior e anterior à formulação prescritiva e normativa. Temos em nós, analogicamente como por paternidade/maternidade, algo de manutenção da sobrevivência futura, como veremos adiante. Assim, o imperativo começa a configurar-se. "Que sempre no futuro deva haver mundo como tal - apto para que o homem o habite... (é o) axioma geral... como obrigação prática para com a posteridade de um futuro distante e como princípio de decisão para a ação presente, [...] (trata-se da)... obrigação de garantir no futuro a premissa primeira de toda obrigação, isto é, justamente a existência de candidatos a um universo moral no mundo físico". (38) Não se pode deixar de lembrar o conceito de base do desenvolvimento sustentável elencado na Rio-92, quando enuncia que o desenvolvimento presente deve deixar condições semelhantes ou melhores às gerações futuras. Em todo caso, temos já um princípio de decisão elencado, para a ação, ou seja, o de existir sujeitos como nós que também têm a obrigação intrínseca de garantir os próximos sujeitos, e assim por diante. Acima de tudo, são sujeito de deveres. E isto é ontológico e virá mais pelo sentimento do que pela razão.

\section{Velhos e novos imperativos éticos}

Na continuação da crítica à ética tradicional, Kant é o ícone a ser questionado, no mesmo modelo que apresentamos antes a crítica ao principialismo e seu formalismo.

O imperativo categórico de Kant dizia: 'Opera de tal modo que possas querer também que tua máxima se converta em lei universal'. Aqui, toda a reflexão fundamental da moral não é ela mesma moral, senão lógica; o 'poder querer' ou 'não poder querer' expressa autocompatibilidade ou auto-incompatibilidade lógica, não aprovação ou desaprovação moral. Mas não há autocontradição em que a humanidade deixe um dia de existir, e tampouco na idéia de que a felicidade das gerações presentes seja obtida a custa da infelicidade ou até inexistência das gerações posteriores... (39).

Já que não nos cabe aqui discutir a amplitude desta crítica, vamos direto ao novo imperativo jonasiano:

"Obra de tal modo que os efeitos de tua ação sejam compativeis com a permanência de uma vida humana autêntica na Terra". Ou, "não ponhas em perigo as condições da continuidade indefinida da humanidade na Terra"... (41).

Nas duas observações de Jonas que se seguem, a primeira diz que não há problema em arriscarmos a nossa vida pessoal, em nos colocarmos em risco ou que façamos de nossa liberdade o que nos aprouver. Contudo, não se pode dizer o mesmo da vida da humanidade, incluindo aqui a biosfera e as gerações futuras. É 
como se isso fosse um princípio mais forte do que o da manutenção individual, pois é posto pela natureza em nós e diz respeito à manutenção da coletividade. É neste sentido também que a segunda observação que se segue aprofunda:

O novo imperativo é dirigido mais à política pública do que ao comportamento privado... O de Kant estava dirigido ao indivíduo e seu critério era instantâneo. [...] De fato, as consequêencias reais não são contempladas e o princípio não é o da responsabilidade objetiva, senão o da condição subjetiva de minha autodeterminação. O novo imperativo apela à concordância não do ato consigo mesmo, mas à concordância de seus efeitos últimos com a continuidade da atividade humana no futuro. [...] $\mathrm{E}$ a sua universalização não é hipotética, ou seja, não é mera transferência lógica do "eu" individual a um "todo" imaginário e sem nenhum vínculo causal com aquele ("se todos procedessem assim"). Antes, as ações submetidas ao novo imperativo... têm sua referência universal na medida real de sua eficácia. (41)

\section{Ética orientada para o futuro e Responsabilidade}

O não existente não tem um lobby e os não nascidos carecem de poder... (56).

Não podemos viver como se fôssemos a última geração (J. Lutzemberger).

[...] da ética há que decidir pela sua existência. E tem que existir porque os homens atuam, e a ética está para ordenar as ações e regular seu poder (59).

Talvez o grande mote da ética de Jonas seja a inclusão dos não-nascidos. 0 "primeiro dever" desta ética orientada ao futuro será justamente a procura pela representação dos efeitos remotos. Impõe-se uma vigilância constante, coletiva, quanto aos possiveis efeitos das intervenções teçnológicas e econômicas. Em tese, poucos se oporiam a tal. Já o "segundo dever", diz respeito à apelação a um sentimento apropriado ao representado. A saber, a heurística do temor e o princípio de precaução estão novamente no fundo. Tal temor, que antes aproximei de uma pedagogia da catástrofe, utilizada muitas vezes no ecologismo, não quer ser um medo à Hobbes, "um temor de caráter 'patológico'... senão de um temor de caráter espiritual... que é obra nossa". Torna-se um pouco ambíguo se pensarmos isto ajuntando a seguinte afirmação: "a questão é se podemos ter uma ética sem recuperar a categoria do sagrado, a qual foi totalmente destruída pela ilustração científica" (58). Não obstante, a posição de Jonas aqui parece dupla, pois refere-se a um fundamento ontológico universal da preservação da vida e do futuro, que desobriga propriamente um fundamento religioso, no sentido da crença no divino; ao mesmo tempo, sabemos que o caráter do sagrado, ligado ao romantismo, e em autores como Heidegger influenciando Jonas, tem um papel considerável. Em todo caso, trata-se aqui de uma ética apelando à metafísica, a um tipo de "biologia fundamental", e à alteridade que atravessa o humano, podendo ser pensada não em termos de rigidez fundamentadora, mas na pluralidade de perspectivas a serem vivenciadas em cada caso. É neste sentido que Jonas não rejeita a deontologia e o caráter da normatividade, mesmo que apele para uma ética calcada, reafirmamos, mais no "sentimento" do que na Razão. 
Em todo caso, podemos atuar em mais de um âmbito de fundamentação da ação. Já falamos em responsabilidade ontológica, mas outro deles, muito prático, é o da responsabilidade objetiva, de que alguém deve sempre responder pelo efeito deletério do ato no ambiente ou na pessoa, independente de sua certeza quanto à causalidade do ocorrido. É por isso que ele prega a "prevalência dos prognósticos maus sobre os bons", apontada sempre para a precaução. "... postergar... quem sabe será demasiado tarde..." (70). Lembremos novamente que é o fato dessa incerteza que "tem que ser incorporada à teoria ética e tomada como ocasião de um novo princípio que possa resultar efetivo como preceito prático" (71). Portanto, se tal cláusula é claramente estabelecida nos tratados, documentos, normas e outros meios onde é referida a ética in toto, mais um motivo para a validação da responsabilidade objetiva.

\section{A aposta e os pontos da nova ética}

Pesa sobre nós a herança que recebemos, o planeta ainda vivo, e pesa sobre nossos ombros justamente no momento de ameaça de perdas irreparáveis, incluída aqui certa alteração da essência ética do ser humano. De algum modo, muitos apostam para além do temor e da precaução em pauta. Apostam para além da responsabilidade ampla e irrestrita, pois jogam para frente, ou colocam 'a poeira em baixo do tapete'. A ética de Jonas, alerta contra tais apostas, pois: A humanidade não tem direito ao suicídio. Não é lícito incluir em minha aposta os interesses dos outros. O aperfeiçoamento tecnológico não justifica a aposta total. Não é lícito apostar a existência do "homem".

$\mathrm{O}$ que Jonas se propõe é investigar, em meio às apostas em jogo, em meio às concepções práticas da ação e suas fundamentações, uma realidade mais concreta, mais fundamental, inadiável, um absoluto, o qual, uma vez chegado a ele, vivencialmente, e no acordo coletivo, ou seja, autenticamente, surgirá o dever correspondente. "Chega-se assim à comprovação de que, entre as apostas em jogo... se encontra uma realidade metafísica, um absoluto que por ser o bem mais alto e mais vulnerável encomendado à nossa tutela, nos impõe como primeiro dever sua conservação". (75). O Conceito de Rosto em Levinas, justamente aquele que rompe com todo conceito e identificação e se revela em sua fragilidade e demanda ética radical, ajuda-nos a compreender que se trata da experiência ética profunda do humano no encontro com o Outro, aqui no mais largo e concreto sentido do outro como outro que me apela. A nova geração e os seres frágeis me apelam e me despertam por sua alteridade. Jonas vai falar do sentimento despertado ou o sentido profundo desta ética em analogia a um arquétipo intrínseco ao humano. Fazemos a experiência de amor aos filhos cotidiana e historicamente; tal é uma experiência poderosa e arrebatadora.

Neste sentido, pontualmente, a Nova Ética:

É não-recíproca, diferente da obrigação de direitos e deveres tradicionais.

- Exige responsabilidade objetiva e não apenas subjetiva. 
- É auxiliada pelo poderoso arquétipo posto em nós pela Natureza: o amor aos filhos.

- Visa mais o DEVER dos descendentes do que seus Direitos. É o dever de conformar a autêntica humanidade, e então a essência humana aceitável.

- Trata-se também de responsabilidade ontológica, pela idéia de homem que deve necessariamente realizar-se.

- Deve haver algo antes que nada? Sim, viver é melhor do que não. Ao não-ser prevalece o Ser. Portanto, a nova ética está fundada concretamente no sentido primeiro da ação humana e sua essência.

- Ao contrário do estabelecido, ele diz que do SER pode derivar um DEVERSER. A Metafísica é base da Ética. Ao Tu deves ético deve preceder um Tu és antropológico.

- Conta com a fé na Vida/Homem, mas também se vale da razão. Não obstante, busca os fundamentos do ser para além da tradição antropocêntrica.

- Isso se liga aos valores e ao Bem, os quais exigem a existência "feliz" (temos aqui dois mandamentos primeiros: Viver, e viver bem, a saber, com outrem). O que faz aflorar um dever-ser intrínseco, ligado ao valor da Vida e sua continuidade.

- A responsabilidade deve contemplar as coisas sub specie temporis, e não no modo aeternitatis. A vulnerabilidade está na base. O modelo aqui é o bebê. Vivemos a responsabilidade pelo perecível como tal, pela alteridade, e este é o ponto alto.

\section{Como conclusão}

Nosso objetivo é reflexivo, e, portanto, que o leitor coteje a crítica aos limites das éticas tradicionais, em especial visando o papel do principialismo em bioética, como apresentamos antes, com a apresentação da essência da proposta de Hans Jonas, no sentido de ver a amplitude colocada, em termos de fundamentação, especialmente ética e epistemológica, e também do caráter de crítica social, à técnica, ao capitalismo e ao caráter privado de certos modelos morais e de resolução de problemas práticos envolvidos na ação humana. O alargamento de Jonas diz respeito a um fundamento novo, paradoxalmente metafísico, naturalista e da alteridade, diante dos dilemas éticos e do que se trata com a essência do homem e sua preservação. Independentemente do ponto de vista adotado, temos aí um autor com alta capacidade de reflexão e compreensão da ação humano no mundo tecnológico, e que transita sem dogmas em torno de grandes modelos de fundamentação do homem, da natureza e da ética, como citamos.

Para finalizar, nada melhor do que a passagem marcante sobre a alteridade na obra citada, e que revela ao nosso ver toda força buscada por Jonas para fundamentar sua ética diante da ameaça à humanidade do homem e a tudo o que contempla o caráter de diferença, que, queiramos ou não, exige sempre a responsabilidade como resposta, pois estamos embarcados na existência, com outros seres, humanos e não-humanos. 
[...] o "outro"... como efetivamente ele mesmo em seu direito próprio, e sem que essa alteridade seja assimilada a mim... Precisamente, a alteridade toma posse de minha responsabilidade, e aqui não se pretende apropriação alguma... Percebido em sua fugacidade, precariedade, insegurança, tem a força de mover-me pela sua pura existência, colocando minha pessoa a sua disposição. E é claro que pode ocorrer assim, pois senão não haveria nenhum sentimento desejável da experiência do summum bonum. (156).

\section{Referências básicas}

BEAUCHAMP, T.; CHILDRESS J. Principles of Biomedical Ethics. 4. ed. New York: Oxford, 1994.

BUCHANAN, A. E.; BROCK, D. W. Deciding for others. The ethics of surrogate decision making. New York: Cambridge University Press, 1989.

CLOTET, Joaquim. Bioética, uma aproximação. Porto Alegre: EDIPUCRS, 2003.

DINIZ, Débora. O que é bioética? São Paulo: Brasiliense, 2002.

ENGELDHARDT, H. T. Bioethics and secular humanism: the search for a common morality. London: SCM Press, 1991.

GARRAFA, Volnei; FERREIRA, Sérgio I. Bioética no século XXI. Brasília:Ed. da UnB, 2000.

GRACIA, Diego. Fundamentos de Bioética. Madrid: Eudema, 1989.

GOROVITZ, S. et al. Moral problems in Medicine. New Jersey: Prentice-Hall, 1976.

JONAS, Hans. Técnica, medicina y etica. Barcelona: Paidós Iberica, 1996.

1979

- Das Prinzip Verantwortung - Versuch einer Ethik für die Technologische Zivilisation. Berlin:

_. El principio de responsabilidad. Barcelona: Herder, 1995.

KANT I. Grundlegung zur Metaphysik der Sitten. Hamburg: Felix Meiner, 1965.

LEVINAS, E. Totalité et infini. Paris: Martinus Nijhof, 1964.

MARTINS, Paulo Henrique. Contra a desumanização da medicina. Petrópolis: Vozes: 2003.

PELIZZOLI, Marcelo L. Correntes da ética ambiental. Petrópolis: Vozes, 2003.

—_. A emergência do paradigma ecológico. Petrópolis: Vozes, 1999.

- Levinas: a reconstrução da subjetividade. Porto Alegre: EDIPUCRS, 2002.

—. O eu e a diferença: Husserl e Heidegger. Porto Alegre: EDIPUCRS, 2002.

- Ética Ambiental e epistemologia. In: Revista Portuguesa de Filosofia, v. 59, fasc. 3, jul.-set. $2003 a$.

PESSINI, L.; BARCHIFONTAINE, C. P. (Orgs.). Fundamentos da Bioética. São Paulo: Paulus, 1996.

POTTER, V.R. Global Bioethics. East Lansing: Michigan State University Press, 1988.

ROTHMAN, David J. Strangers at the Bedside: a history of how law and bioethics transformed medical decision making. USA: Basic Books, 1991.

SÉVE, L. Pour une critique de la raison bioétique. Paris: Editions Odile Jacob, 1994.

VEATCH, R. Medical Bioethics. Boston: Jones and Bartlett, 1997 